\title{
Fotokatalitik yöntemlerle pestisit giderimi: Clothianidin örneği
}

\author{
Güray Salihoğlu ${ }^{1 *}$, Gizem Evrim Dilcan ${ }^{1}$, Mojca Kralj ${ }^{2}$, Polonca Trebse ${ }^{2}$ \\ ${ }^{1}$ Bursa Uludă̆ Üniversitesi, Mühendislik Fakültesi, Çevre Mühendisliği Bölümü, 16059, Bursa, Türkiye (ORCID: 0000-0003-0714-048X) \\ ${ }^{2}$ University of Ljubljana, Faculty of Health Sciences, Slovenia
}

(İlk Geliş Tarihi 1 Temmuz 2019 ve Kabul Tarihi 9 Ağustos 2019)

(DOI: $10.31590 /$ ejosat.600236)

\begin{abstract}
ATIF/REFERENCE: Salihoğlu, G., Dilcan, G.E., Kralj, M. \& Trebse, P. (2019). Fotokatalitik yöntemlerle pestisit giderimi:
\end{abstract} Clothianidin örneği. Avrupa Bilim ve Teknoloji Dergisi, (16), 855-862.

\begin{abstract}
$\ddot{\mathbf{O z}}$
Neonikotinoid grubu pestisitler, nikotine benzeyen davranışlarıyla sinir dokularını etkileyen insektisitlerdir. Bu insektisit grubunun özellikle balarısı kolonileri üzerindeki ölümcül etkileri bilinmektedir. Bunun yanındaki diğer olumsuz ekolojik etkileri nedeniyle bazı türlerinin kullanımı çeşitli ülkelerde yasaklanmıştır. Neonikotinoid grubundan bir insektisit türü olan Clothianidin, su ve toprak gibi çevresel ortamlarda bulunabilen yasaklanmış insektisit türlerinden biridir. Clothianidin kalıcı ve yüksek hareketliliğe sahip, hidrolize dirençli, yeraltısuyuna ve yüzeysel sulara sızma potansiyeline sahip bir neonikotinoid grubu pestisit türü olarak bilinmektedir. Clothianidinin görünür 1şık karşısındaki fotodegradasyon davranışını belirlemek ve arıtma formülasyonları geliştirmek bu kirleticilerle kirlenmiş atıksuların yönetiminde önemlidir. Bu çalışmanın amacı, Clothinanidin'in ileri oksidasyon yöntemleriyle giderim etkinliğini araştırmaktır. Çalışma kapsamında Clothianidin'in UV-A, UV-C ışınları karşısındaki kararlılığının yanında TiO ve oksijen desteği ile su içerisindeki fotokatalitik bozunması da araştırılmıştır. Clothianidinin sulu çözeltisi 0-120 dakika arasında değişen süreler boyunca $\mathrm{UV}-\mathrm{A}, \mathrm{UV}-\mathrm{A}+\mathrm{TiO}_{2}, \mathrm{UV}-\mathrm{A}+\mathrm{TiO}_{2}+\mathrm{O}_{2}$ ve $\mathrm{UV}-\mathrm{C}$ uygulamalarına tabi tutulmuş, süreç esnasında değişen Clothianidin konsantrasyonu HPLC analizleriyle izlenmiştir. UV-A uygulamasına tabi tutulan çözeltideki Clothianidin düzeyinin sabit kaldığı, kirleticinin herhangi bir bozunmaya uğramadığı gözlenmiştir. Ancak $\mathrm{TiO}_{2}$ varlığında yapılan UV-A uygulaması, herhangi bir giderim etkisi göstermeyen UV-A uygulamasına göre uygulama süresiyle artan bir Clothianidin giderim eğilimiyle sonuçlanmıştır. $\mathrm{UV}-\mathrm{A}+\mathrm{TiO}_{2}$ uygulamasının \%42 oranında bir giderimle sonuçlandığı görülmüştür. UV-A+TiO 2 sürecine oksijen ilave edilerek yapılan uygulamada ise oksijenin Clothianidin'in bozunmasına olumlu bir etkisinin olduğu, giderim veriminin artarak \%42'den \%69 düzeyine ulaştığı görülmüştür. UV-C uygulaması ile 5 dakika gibi kısa bir sürede \%99'a varan bir giderim verimi elde edilmiştir. TiO ${ }_{2}$ ve oksijen varlığında gerçekleştirilen fotokatalik yöntemin ve özellikle UV-C uygulamasının diğer yöntemlerden çok daha etkili olduğu ve arıtma çözümlerinde tercih edilebileceği sonucuna varılmıştır.
\end{abstract}

Anahtar Kelimeler: Neonikotinoid, ileri artıma, $\mathrm{TiO}_{2}, \mathrm{UV}-\mathrm{A}, \mathrm{UV}-\mathrm{C}$, fotoliz

\section{Pesticide removal by photocatalytic methods: Clothianidin example}

\begin{abstract}
Pesticides from neonicotinoids family are known to be insecticides that are effective on neural tissues acting chemically similar to nicotine. Their detrimental effects, especially on honey-bee colonies, are well researched. Their other adverse ecological effects leaded restrictions on the usage of several members of this pesticide class in many countries. Clothianidin, an insecticide species from the group of neonicotinoids, is one of the banned insecticide species that can be found in environmental environments such as water and soil. Clothianidin is known as a persistent, mobile, and resistant to hydrolyze and has the potential to leach into groundwater or reach surface waters. It is important to determine the photodegradation ability of Clothianidin under the visible light and develop treatment formulations in the management of wastewaters polluted with this insecticide. This study aimed to investigate the efficacy of Clothianidine removal by advanced oxidation methods. For this purpose, UV-A, UV-C stability was investigated and additional effects of $\mathrm{TiO}_{2}$ and oxygen addition on oxidation options were determined. Clothianidin solution was subjected to UV-A, UV-C, UV$\mathrm{A}+\mathrm{TiO}_{2}$, and $\mathrm{UV}-\mathrm{A}+\mathrm{TiO}_{2}+\mathrm{O}_{2}$ for changing durations between 0-120 minutes, and degradation process was monitored by conducting HPLC analyses. UV-A stability experiments showed that Clothianidin solution stayed stabile and did not degrade under UV-A. UV-A
\end{abstract}

\footnotetext{
${ }^{1}$ Sorumlu Yazar: Bursa Uludağ Üniversitesi, Mühendislik Fakültesi, Çevre Mühendisliği Bölümü, Bursa, Türkiye, ORCID: 0000-0003-0714-048X, gurays@uludag.edu.tr
} 
application conducted in the presence of $\mathrm{TiO}_{2}$ showed an increasing removal efficiency by time compared to UV-A application. UV$\mathrm{A}+\mathrm{TiO}_{2}$ application resulted in removal efficiency of $42 \%$. When oxygen was introduced to the $\mathrm{UV}-\mathrm{A}+\mathrm{TiO} \mathrm{O}_{2}$ application, oxygen contributed to the degradation of Clothianidin and the removal efficiency increased to $69 \%$ from $42 \%$. Removal efficiency up to $100 \%$ was achieved when UV-C was applied for a short time, such as 5 minutes. The experimental findings showed that photocatalytic removal of Clothianidine pesticide was possible when $\mathrm{TiO}_{2}$ and oxygen were added and especially UV-C method was found to be more effective than the other methods and can be a preferred step in treatment solutions.

Keywords: Neonicotinoids, advanced oxidation, $\mathrm{TiO}_{2}$, UV-A, UV-C, photolysis.

\section{Giriş}

Bitki zararlılarını önlemek, püskürtmek veya yok etmek amacıyla kullanılan kimyasal ya da biyolojik ürünlerin tümüne pestisit adı verilmektedir. Kimyasal ve fiziksel özellikleri nedeniyle bazı pestisitlerin hedef olmayan organizmalar için toksik etkiler gösterdiği bilinmektedir. Bileşiğin kendine özgü özelliklerine bağlı olarak kalıcılık, biyolojik birikim potansiyeli ve toksisite gibi özellikler gösterebilen pestisitler, hedef canlıların dışında, mikroorganizmalar, omurgasızlar, bitkiler ve balıklar gibi hedef olmayan organizmaları da etkileyebilmektedir (Kohler ve Triebskorn, 2013; Le ve diğ., 2017). Kullanıldıkları zararlı canlı gruplarına ya da hedef alınan organizmaya göre, insektisit, fungusit ve herbisitler üç büyük pestisit grubu olarak karşımıza çıkmaktadır. Tarımsal uygulamalarda sürekli olarak aynı insektisit türlerinin kullanılması, böcek türlerinin zamanla bu insektisitlere karşı duyarlılığını kaybederek dirençli duruma gelmesine neden olmaktadır. Bu durum, bu kimyasal maddelerin sürekli olarak yenilenme gereksinimini ortaya çıkarmaktadır (Fırat ve Aytekin, 2018). Hemen hemen tüm pestisit türlerinin, özellikle çok kalıcı olan organoklorlu pestisit gruplarında kronik toksisite etkileri bilinmektedir. Bunun yanında geçmişte kitlesel ölümlere neden olmuş olan DDT gibi organoklorlu pestisitlerin akut akut toksik ve endokrin bozucu özellikleri bilinmektedir. Fare, kuş ve balıklardaki östrojenik ve/veya androjenik etkileri rapor edilmiştir (Kohler ve Triebskorn, 2013). Bugüne kadar farklı kimyasal sinıflarda yer alan 120'nin üzerinde pestisit türünün endokrin bozucu özellikleri ortaya konmuştur (Kohler ve Triebskorn, 2013). Organoklorlu, organofosfatlı ve karbamat türü pestisitlerin kemirgen, böcek, amfibiler ve balıklarda tiroid bozukluğuna neden oldukları bilinmektedir. Organofosforlu pestisit türlerinin immünotoksik etkileri, omurgalılarda su ve gıda alımı ve davranış (aktivite, yiyecek arama süresi, öğrenebilme becerisi) metabolizmasında olumsuz etkilerinin olduğu rapor edilmiştir (Paskova ve diğ., 2011). Bu ve benzeri nedenlerle, uzun yıllardır kullanılan organoklorlu, organofosforlu ve karbamat türü insektisitlerin tarımsal uygulamaları zamanla azalmış, bu insektisit türlerine alternatif olarak piretroit ve daha sonraları da neonikotinoid türü insektisitler geliştirilmiştir (Kovganko ve Kashkan, 2004).

Neonikotinoidler, insektisitlerin yeni bir sınıfı olup 30 yıldır tarımsal uygulamalarda kullanılmaktadır. Yapılan araştırmalar, 1990 yılında tarımsal markette $\% 43$ oranında organofosforlu, \%18 oranında piretroid, \%16 oranında karbamatlı pestisitler kullanılırken, günümüzde $\% 80$ oranında yeni sistemik insektisit grubu olan neonikotinoidlerin kullanıldığını göstermektedir (Jeschke ve diğ., 2011). Karbamatlı, organofosoforlu, piretroid ve fibronil pestisit gruplarının kullanımlarının sırasıyla $\% 8, \% 3$, \%2 ve \%8'e indiği bilinmektedir (Jeschke ve diğ., 2011).

Neonikotinoidler sinir dokuları üzerinde etkin olan ve nikotine benzeyen pestisitlerdir. Neonikotinoid grubu pestisitlerden imidacloprid, thiamethoxam ve clothianidin, pamuk, mısır, tahıllar, şeker pancarı ve diğerleri gibi farklı mahsullerde tohum iyileştirmesi için yaygın olarak kullanılmaktadır (Jeschke ve diğ., 2011). Clothianidin, yaprak bitleri, beyazsinekler ve tırtıllara karşı özellikle etkilidir. Çeşitli böcek türleri (örneğin Diabrotica spp.) bazı sinek türleri (örneğin, Oscinella frit ve Pegomyia spp.) ve kemirici kurtlar (örneğin, Agriotes spp) için de aktif bir kontrol aracı olarak kullanılmaktadır (Jeschke ve diğg., 2011).

Birçok organizma türü için az toksik etkili olarak tanıtılmış olan neonikotinoidlerin bal arıları ve bazı diğer faydalı böcek türleri için düşük temas düzeylerinde bile potansiyel toksik etkili olabildikleri öne sürülmüştür (Jeschke ve Nauen, 2008). Neonikotinoidler, arıların, gıda kaynaklarına ulaşma yollarını öğrenme ve hatırlama gibi beslenme amaçlı uçuş kabiliyetlerini etkileyebilmektedirler (Whitehorn ve diğ., 2012). Öldürücü dozun altındaki miktarlara maruz kalmaları bile arı davranışlarını değiştirerek kolonilerin hayatta kalmasını güçleştirebilmektedir (Whitehorn ve diğ., 2012).

Tokumoto ve diğ. (2013) tarafından yapılan bir çalışmada, bir neonikotinoid türü olan Clothianidin'in 2008 yılında Japonya'da bazı pirinç tarlaları ve çiftliklerde kullanılması nedeniyle, bu alanları habitat olarak kullanan ve nesli tükenmekte olan Nipponia nippon türü kuşların yumurtalarının 3 yıl sonra döllenmediği gözlenmiştir.

Olumsuz ekolojik etkileri nedeniyle neonikotinoid pestisit ailesi içinde bazı türlerin kullanımı çeşitli ülkelerde yasaklanmıştır. 2013 y1lında Avrupa Komisyonu, balarılarını korumak için Clothianidin, Imidacloprid ve Thiamethoxam neonikotinoidlerinin bitki koruma ürünlerinde kullanımını yasaklamıştır (EU, 2013). Türkiye'de 19.12.2018 tarihli Tarım ve Orman Bakanlığı Gıda ve Kontrol Genel Müdürlüğü tarafından çıkarılan genelgede (TOB, 2018), Clothianidin aktif maddesinin zararlarına değinilmekte ve Clothianidin ithalatının 08.02.2019 tarihine kadar, bu maddeyi içeren ürünlerin kullanımının ise 31.07.2019 tarihine kadar sonlandırılması gerektiği belirtilmektedir.

Neonikotinoidlerin su içindeki akıbeti 1şık, pH, sıcaklık, formülasyon ve mikrobiyal aktiviteye bağlıdır (Anderson ve diğ., 2015). Clothianidin kalıcı ve yüksek hareketliliğe sahip, hidrolize dirençli, yeraltısuyuna ve yüzeysel sulara sızma potansiyeline sahip bir neonikotinoid grubu pestisit türü olarak bilinmektedir (USEPA, 2003). Yamamoto ve diğ. (2012) tarafından yapılan bir çalışmada Japonya'nın Osaka kentindeki ve civardaki nehirlerden su örnekleri $(n=45)$ toplanmış ve neonikotinoid düzeyleri belirlenmiştir. Örneklerin \%91'inde Clothianidin belirlenmiş ve $3.2 \times 10-3 \mu \mathrm{g} / \mathrm{L}$ düzeyinde bir ortalama konsantrasyon rapor edilmiştir (Yamamoto ve diğ., 2012).Neonikotinoidler çok küçük miktarlarda bile böcekler üzerinde toksik etki gösterebilirler. Örneğin arılar tarafından ağız yoluyla alınan Imidacloprid ve Clothianidin'in böcek başına 4-5 ng miktarı popülasyonun \%50'sinin ölümüne neden olmaktadır 
(LD50 : 4-5 ng/böcek) (Goulson, 2013). Bu oran DDT pestisiti için bilinen ölümcül dozun 1/10000'i seviyesindedir (Goulson, 2013). Suda kolayca çözünen neonikotinoidler bileşiğin yapısına ve toprak tipine bağlı olarak toprakta belli bir yarılanma ömrüne sahiptirler. Yapılan çalışmalarda Clothianidin'in topraktaki yarılanma ömrünün 148 ila 6931 gün arasında değiştiği görülmektedir (Goulson, 2013).

Zararlı etkileri bilinen ve canlı maruziyetinin kaçınılmaz olduğu pestisitlerin giderim mekanizmalarının ve yöntemlerinin araştırılması, riski azaltmak açısından önemlidir. Son yıllarda çeşitli pestisit türleri için UV fotolizinin verimli sonuçlar verdiği (Burrows ve diğ., 2002), ileri oksidasyon süreçlerinin pestisit gideriminde etkili olduğu çeşitli araştırmacılar tarafından rapor edilmiştir (Badawy ve diğ., 2006; Chiron ve diğ., 2000; Konstantinou ve Albanis, 2003). UV radyasyonunun istenmeyen mikroorganizmaların DNA yapısını parçaladığı, sonuç olarak fotokimyasal süreçlerin gerçekleştiği belirtilmiştir (Burrows ve diğ., 2002). Heterojen titanyum dioksit $\left(\mathrm{TiO}_{2}\right)$ fotokatalizi (Burrows ve diğ., 2002; Cernigoj ve diğ., 2007), foto-Fenton reaksiyonu (Martin ve diğ., 2009), yaygın olarak uygulanan yöntemler arasındadır. Zabar ve diğ. (2011) Tiametoksam, Imidacloprid ve Clothianidin'in sulu çözeltilerinin immobilize edilmiş $\mathrm{TiO}_{2}$ ile fotokatalitik bozulmaya karşı duyarlılı̆̆ını araştırmışlar ve $\mathrm{TiO}_{2}{ }^{\prime} \mathrm{in}$ bu neonikotinoidlerin bozunması açısından iyi bir katalizör olduğunu belirtmişlerdir.

Clothianidin pestisitinin giderimi konusunda yapılan çalışmalar çok sınırlı sayıda ve düzeydedir. Kullanımı oldukça yaygın olan ve özellikle sucul çevresel ortamlara giriş yapmış olan bu pestisitin giderimiyle ilgili farklı ileri oksidasyon yöntemlerinin detaylı olarak araştırılması ihtiyacı bulunmaktadır. Clothianidinin görünür ışık karşısındaki fotodegradasyon davranışııı belirlemek ve arıtma formülasyonları geliştirmek bu kirleticilerle kirlenmiş atıksuların yönetiminde önemlidir. Bu çalışmanın amacı, Clothinanidin'in ileri oksidasyon yöntemleriyle giderim etkinliğini araştırmaktır. Bu amaçla UV-A, UV-C stabilitesi araştırılmış, $\mathrm{TiO}_{2}$ ve oksijen ilavesinin oksidasyon seçenekleri üzerindeki etkileri belirlenmiş̧ir.

\section{Materyal ve Metot}

Çalışmada sentetik olarak hazırlanan $10 \mathrm{mg} / \mathrm{L}$ Clothianidin sulu çözeltisi 0-120 dakika arasında değişen süreler boyunca UV-A, UV-C, UV-A $+\mathrm{TiO}_{2}$ ve UV-A $+\mathrm{TiO}_{2}+\mathrm{O}_{2}$ uygulamalarına tabi tutulmuştur. Çalışmada Dr. Ehrenstorfer $\mathrm{GmbH}$ (Augsburg, Germany, EU) marka, $\% 99,25(\mathrm{~g} / \mathrm{g})$ saflıkta toz halde Clothianidin ve Linde Kisik marka \%99,5 saflıkta Oksijen, Sigma-Aldrich (St. Louis, Missouri, USA) marka asetik asit ve asetonitril (HPLC Yüksek Performanslı Siv1 Kromatografisi-High Performance Liquid Chromatography kalitesi Chromasolv) kullanılmıştır. Çift deiyonize su (<18 M $\Omega / \mathrm{cm}-)$ nano pure su sistemi (Barnstead, USA) ile hazırlanmıştır.

Çözeltideki Clothianidin düzeyi Agilent 1100 HPLC-UV-Vis kromatografı (Agilent Technologies, Palo Alto, CA, ABD) ile analiz edilmiştir. Ayrışma, Supelco Ascentis ${ }^{\circledR}$ Express $5 \mu \mathrm{m} \mathrm{C18} \mathrm{kolonu}(5 \mu \mathrm{m}, 150 \mathrm{~mm}$ x 4,6 mm) kullanılarak gerçekleştirilmiş̧ir. Sıcaklık $25^{\circ} \mathrm{C}^{\prime}$ ye ayarlanmıştır. Enjeksiyon hacmi $20 \mu \mathrm{L}$ 'dir. Mobil faz $1,0 \mathrm{~mL}$ dk-1 akış hızında olup \%40 asetonitril ve \% 60 asetik asitten (\%1,0'lik) oluşmaktadır. Dalga boyu $260 \mathrm{~nm}$ 'dir. Ölçümleri doğrulamak için, $0,5 \mathrm{mg} / \mathrm{L}$ ila $50 \mathrm{mg} / \mathrm{L}$ aralığında kalibrasyon eğrileri hazırlanmıştır. Analiz için kullanılan viallere $1 \mathrm{ml}$ 'lik hacimlerde numuneler hazırlanmıştır. Hazırlanan örnekler viallerden otomatik örnekleyi sayesinde otomatık olarak kolonlara iletilmesini sağlamaktadır.

Deneylerde $280 \mathrm{~mm}$ çapında (iç çapı $80 \mathrm{~mm}$ ), etkin hacmi $1500 \mathrm{~mL}$ olan Duran marka cam bir reaktör kullanılmıştır. UV-C uygulamaları için kuvartz reaktör hücresi kullanılmıştır. Reaktörün parlak alüminyum kaplı yansıtıcı yüzeyine 6 adet ultraviyole $\mathrm{A}$ (UV-A) lamba (15 W, $265 \mathrm{~mm}$ x $16 \mathrm{~mm}$, Philips Cleo, maksimum $355 \mathrm{~nm}$ genişliğinde) ve 6 adet ultraviyole C (UV-C) lamba (265 mm x $16 \mathrm{~mm}$, Philips Cleo, maksimum $254 \mathrm{~nm}$ genişliğinde) yerleştirilmiştir. Reaktörün şematize edilmiş gösterimi Şekil 1 'de verilmektedir. Reaktör hücresi lambalardan $10 \mathrm{~cm}$ uzaklıkta bulunan merkeze yerleştirilmiştir.

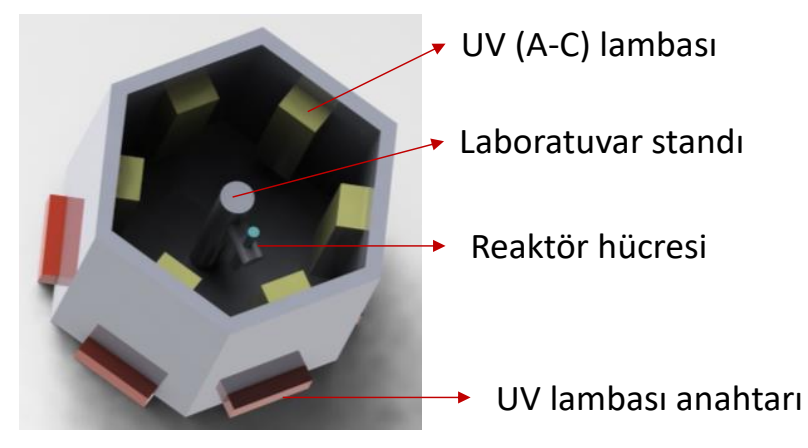

\section{Şekil 1. Deneylerde kullanılan reaktörün şematize edilmiş gösterimi}

Silikon $\left(\mathrm{SiO}_{2}\right)$ kaplamalı cam levhaların her iki yüzeyinde sol-jel işlem tekniğiyle şeffaf $\mathrm{TiO}_{2}$ çökelekleri oluşturulmuştur (Cernigoj ve diğ., 2007). Bu şekilde $\mathrm{TiO}_{2}$ katalizörü cam levhalar üzerinde immobilize edilmiştir. Cam levhaların boyutları $190 \mathrm{~mm}$ x $12,5 \mathrm{~mm}$ x 2 mm'dir. Cam levha üzerine düşen ve tartılarak belirlenen katalizör miktarı $225 \mu \mathrm{g} / \mathrm{cm}^{2}$ düzeyindedir. $\mathrm{TiO}_{2}$ katalizörü ile immobilize edilmiş veya edilmemiş (sürece göre) on iki cam levha, reaktör hücresinin ortasına yerleştirilmiş özel bir teflon tutucu ekseni etrafına sabitlenmiştir. Silindir tüpte bulunan Linde Kisik marka \%99,5 saflıkta oksijen ince boru vasıtasıyla reaktör hücresine iletilmiştir. 


\section{Araştırma Sonuçları ve Tartışma}

\subsection{UV-A Uygulamasıyla Clothianidin Giderimi}

Şekil 2'de Clothianidin sulu çözeltisine 120 dakika boyunca UV-A uygulandığında Clothianidin konsantrasyonlarında görülen değişim verilmektedir. Şekle göre sadece UV-A ışınlarına maruz kalan Clothianidin'in UV-A maruziyeti altında oldukça kararlı durumda kaldığı, konsantrasyon düzeylerinde önemli bir değişim olmadığı görülmektedir.

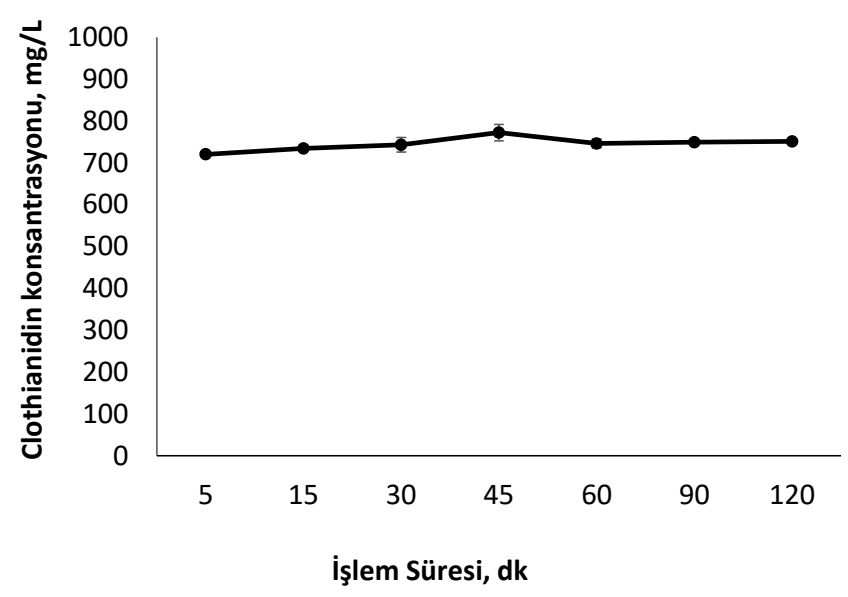

Şekil 2.UV-A uygulamasıyla Clothianidin düzeylerinde görülen değişim

Affam ve Chaudhuri (2013) UV-A ı̧ınları altında Chlorpyrifos, Cypermethrin ve Chlorothalonil pestisitlerinin sulu çözeltilerinin $\mathrm{TiO}_{2}$ ile $\mathrm{H}_{2} \mathrm{O}_{2}$ varlı̆̆ı̆nda giderimlerini araştırmıştır. Bu pestisitlerin $320 \mathrm{~nm}$ 'nin üzerinde UV sşınımını absorbe etmediği ve bu nedenle, UV-A $(365 \mathrm{~nm})$ 1şınlarının tek başına kullanımından kaynaklı kayda değer bir bozunma beklenmediği öne sürülmüştür (Affam ve Chaudhuri, 2013). Bu çalışmada araştırma konusu olan Clothianidin pestisitinin Affam ve Chaudhuri (2013) tarafindan araştırılan Chlorpyrifos, Cypermethrin ve Chlorothalonil pestisitlerine benzer şekilde UV-A maruziyeti altında kararlı olduğu söylenebilir. Clothianidin pestisitinin de diğerleri gibi $320 \mathrm{~nm}$ 'nin üzerindeki UV-A ışınlarına maruz kaldığında fotodegredasyona uğramadığı sonucu çıkarılabilir.

\subsection{UV-A + $\mathrm{TiO}_{2}$ Uygulamastyla Clothianidin Giderimi}

Şekil 3'te UV-A'nin $\mathrm{TiO}_{2}$ ile birlikte uygulanmasıyla Clothianidin düzeylerinde görülen değişim verilmektedir.

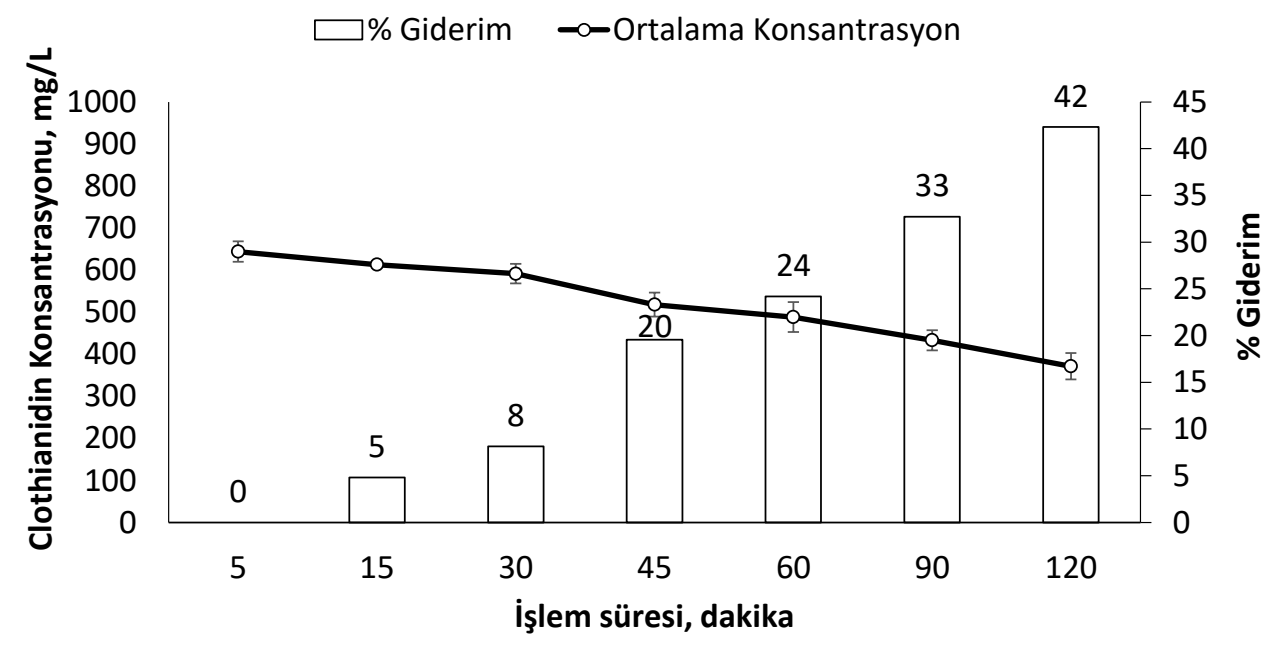

Şekil 3. $U V-A+\mathrm{TiO}_{2}$ uygulamaslyla Clothianidin düzeylerinde görülen değişim 
$\mathrm{TiO}_{2}$ varlığında yapılan UV-A uygulaması, herhangi bir giderim etkisi göstermeyen UV-A uygulamasına göre uygulama süresiyle artan bir Clothianidin giderim eğilimiyle sonuçlanmıştır. 120 dakikalık uygulama sonucunda \% 42 oranında Clothianidin giderimi elde edilmiştir. $\mathrm{TiO}_{2}$ katalizörünün üstün fotokatalitik oksidasyon kabiliyeti olduğu bilinmektedir (Lorret ve diğ., 2009). UV 1şı̆̆ $\mathrm{TiO}_{2}$ gibi yarı iletken partiküllerle birlikte olduğunda, fotonlar yarı iletken tarafindan absorbe edilmekte ve fotokatalitik bir bozunma gerçekleşmektedir (Schneider ve diğ., 2014). Yarı iletken $\mathrm{TiO}_{2}$ katalizörü yeterli enerjiye maruz kaldığında elektronlar (e-) ve

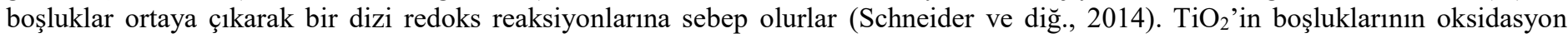
güçlerinin, uyarılan elektronların indirgeme güçlerinden daha fazla olduğu, yüzeyine sıkıca tutunmuş bir su molekülü tabakasının bulunduğu bilinmektedir (Fujishima ve Zhang, 2006). Yüzeye tutunmuş bu su molekülleri boşluklar tarafından oksitlendiğinde, yüksek oksitleme gücüne sahip hidroksil radikalleri $(\bullet \mathrm{OH})$ oluşmaktadır. Hidroksil radikalleri başlangıçta serbest radikaller (paylaşılmamış bir elektronu olan kararsız moleküller) oluşturarak, sonradan organik bileşiklerle reaksiyona girerler (Fujishima ve Zhang, 2006). Ortamda moleküler oksijen olduğu zaman, ortamda bulunan paylaşılmamış elektronlar sayesinde organik peroksil radikalleri oluşturarak serbest radikallerle reaksiyona girerler; bu radikaller, zincir reaksiyonlarda yer alırlar (Fujishima ve Zhang, 2006). Kısa bir süre içerisinde organik bileşiğin tamamen parçalanarak karbon dioksit ve suya dönüşmesi mümkündür (Hashimoto ve diğ., 2005).

Zabar ve diğ. (2011), Tiametoksam, Imidacloprid ve Clothianidin'in sulu çözeltilerinin immobilize edilmiş $\mathrm{TiO}_{2}$ ile fotokatalitik bozulmaya karşı duyarlılığını araştırmışlar ve Tiametoksam'ın \%9,9, Imidacloprid'in \%1.1 ve Clothianidin'in \%8 oranında bozunduğu gözlemlemişlerdir. Bu çalışmada sadece UV-A 1şınlarına maruz bırakılan Clothianidin'de herhangi bir bozunma gözlenmezken, $\mathrm{TiO}_{2}$ varlığında bu pestisitin bozunmaya uğradığı görülmüştür (Zabar ve diğ., 2011). Chu ve Wong (2004) doğrudan fotolizin tek başına oldukça yavaş bir işlem olduğunu, ancak $\mathrm{TiO}_{2}$ katalizörünün UV-A 1şınları ile birlikte kullanılması durumunda reaksiyon hızlarının yaklaşık 3 ila 5 kat arttı̆̆ını belirtmişlerdir.

\subsection{UV-A + $\mathrm{TiO}_{2}+\mathrm{O}_{2}$ Uygulamasıyla Clothianidin Giderimi}

Şekil 4a'da UV-A'nin $\mathrm{TiO}_{2}+\mathrm{O}_{2}$ ile birlikte uygulanmasıyla Clothianidin düzeylerinde görülen değişim görülmektedir. Şekil 4b'de ise elde edilen giderim verimleri $\mathrm{O}_{2}$ ilavesinin yapılmadığ $\mathrm{UV}-\mathrm{A}+\mathrm{TiO}_{2}$ uygulamasının giderim verimleriyle karşılaştırılmaktadır.

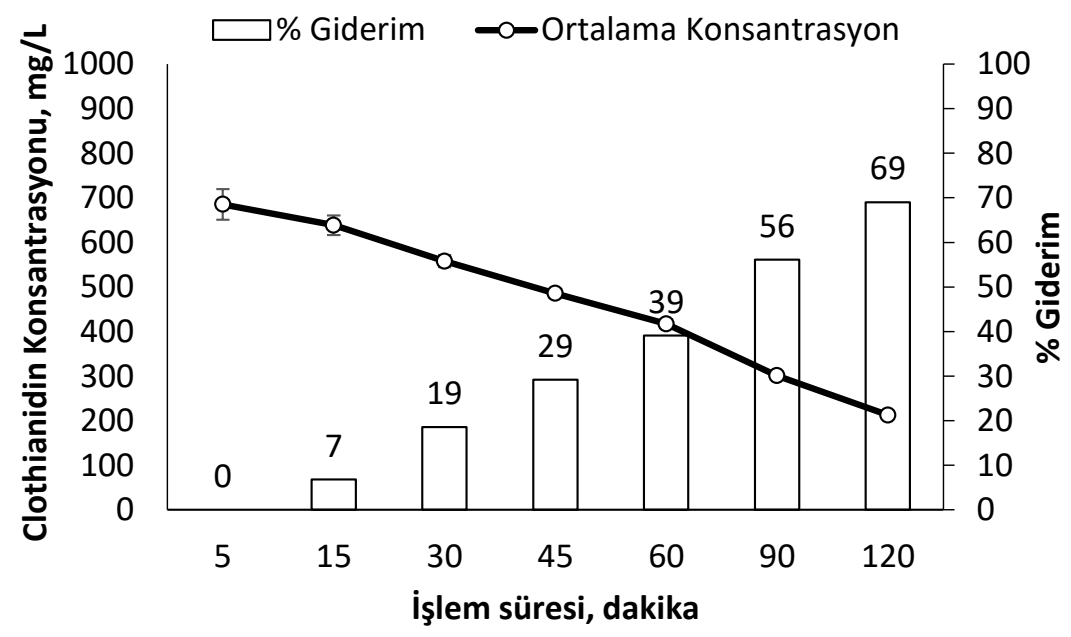

a)

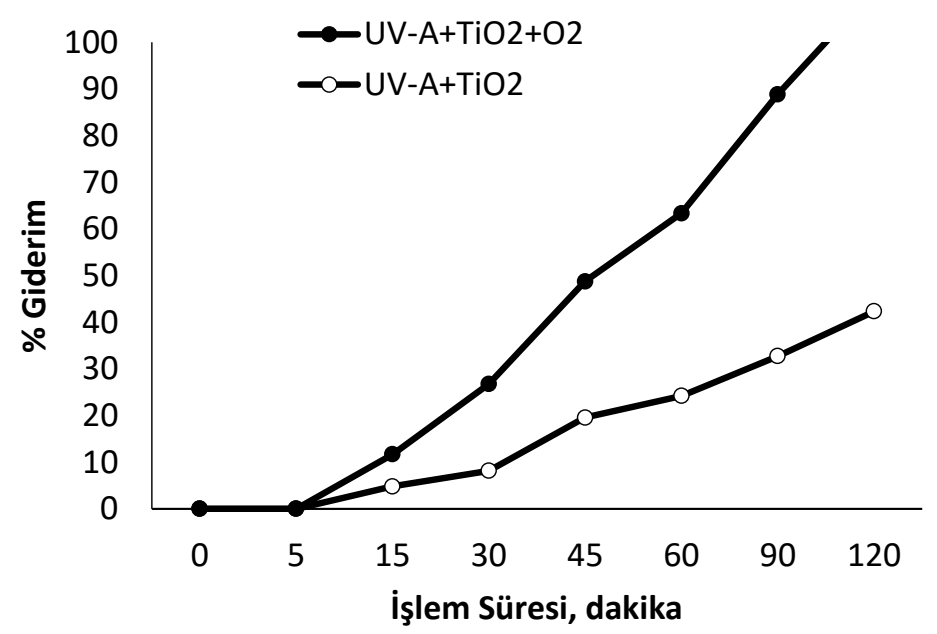


b)

\section{Şekil 4. $\mathrm{UV}-\mathrm{A}+\mathrm{TiO}_{2}+\mathrm{O}_{2}$ uygulaması, a) Clothianidin düzeylerinde görülen değişim, b) Giderim verimlerinin $\mathrm{O}_{2}$ 'nin uygulanmadı ̆̆ durumla karşılaştırılması}

Sürece oksijen ilave edilerek yapılan uygulamada oksijenin Clothianidin'in bozunmasına olumlu bir etkisinin olduğu gözlenmiştir. Şekil 4a'da Clothianidin gideriminin 120 dakika sonunda \%69 düzeyine ulaşabildiği görülmektedir. Şekil 4b'de görüldüğg̈ gibi $\mathrm{O}_{2}$ 'nin olmadığı uygulamada aynı sürede verim $\% 42$ düzeyine ulaşabilmiştir.

Banic ve diğ. (2016) \%70 Imidacloprid içeren Confidor 70-WG, \%44,4 Tiacloprid içeren Calypso 480-SC, \%20 Acetamiprid içeren Mospilon 20-SP VE \%25 Thiomethoxam içeren Actora 25-WC neonikotinidlerinin fotokatalitik yöntemlerle giderimini araştırmışlardır. Çalışmada \%44,4 Tiacloprid içeren Calypso 480-SC neonikotinoid UV-A ışınları altında iken, oksijen beslemesi yapılmış ve fotokatalitik giderim belirlenmiştir (Banic ve diğ., 2016). Sadece UV-A 1şınlarına maruz bırakılan örnekle UV-A 1şınlarına ilave oksijen beslemesi yapılan örnek karşılaştırıldığında oksijen beslemesinin bozunma verimliliğinin artırdığı gözlenmiştir (Banic ve diğ., 2016). Sonuçlar oksijen varllğının fotokatalitik süreçte etkili bir faktör olabileceğini göstermektedir. Katalizör yüzeyinde adsorbe edilen oksijen, elektron alıcısı olarak hareket etmekte ve bozunma prosesinden sorumlu diğer aktif radikalleri oluşturmaktadır (Banic ve diğ., 2016). Serbest radikaller eşlenmemiş elektron bulundurduklarından dolayı diğer maddelerle kolaylıkla reaksiyona girebilmekte ve insektisitin bozunma verimini artırmaktadırlar. Bu çalışmada Banic ve diğ. (2016) tarafindan rapor edilen bulgulara benzer şekilde oksijeninin fotokatalitik bozunmayı sağlayan aktif radikalleri oluşturarak Clothianidin'in bozunmasını artırdığı söylenebilir.

\subsection{UV-C Uygulamasıyla Clothianidin Giderimi}

Şekil 5'te UV-C uygulamasıyla Clothianidin düzeylerinde görülen değişim verilmektedir.

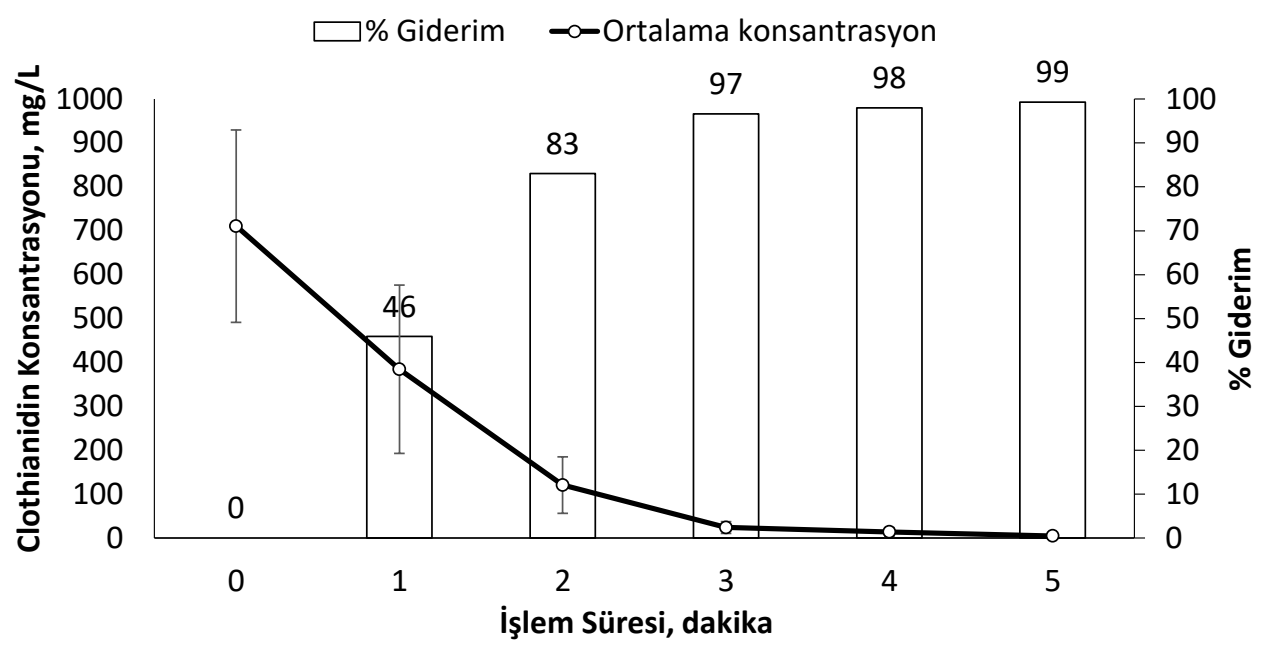

Şekil 5. UV-C uygulamasıyla Clothianidin düzeylerinde görülen değişim

Sadece UV-C ışınına maruz bırakılan Clothianidin'in ilk 5 dakikada neredeyse \%100'e varan bir verimle bozunduğu Şekil 5 'te görülmektedir. Bustos ve diğ. (2019) tarafından Dichlorvos adlı orgonofosfor pestisitinin UV-C (254 nm) 1şıları altında oksijen varlığında ve yokluğunda fotodegredasyonunun araştırıldığ çalışmada sadece UV-C ışınlarına maruz bırakılan örneğin \%71 oranında giderildiği gözlenmiştir. $\mathrm{Bu}$ durumdan yola çıkılarak UV-C ışınlarının reaktif oksijen türleri oluşumuna katkıda bulunduğu gözlenmiștir (Bustos ve diğ., 2019). UV-C ışıklarının organik kirleticilerin giderilmesine neden olan $\mathrm{OH} \bullet$. radikallerinin üretiminde etkin olduğu, bu radikallerin seçici olmayıp tüm organik maddeler ile reaksiyona girerek son ürün olarak $\mathrm{CO}_{2} v \mathrm{H}_{2} \mathrm{O}$ oluşturduğu bilinmektedir (De Laat ve diğ., 1999). Yapılan çalışmada UV-C ışınlarının reaktif oksijen türlerinin oluşumunu artırdığı ve oluşan serbest radikallerin Clothianidin'i hızlı bir şekilde parçaladığı sonucu çıkartılabilir. 


\section{Sonuçlar}

Yaygın olarak kullanılan ve karıştığı çevresel ortamlarda kalıcılık gibi özellikler gösteren, özellikle ekosistemin devamlılığında önemli bir yeri olan balarılarının yok olmasına neden olan neonikotinoid türü bir pestisit olan Clothianidin'in fotokatalitik yöntemlerle giderimi araştırılmıştır. Elde edilen sonuçlar aşağıdaki gibi özetlenebilir:

- Sadece UV-A ışınlarına maruz kalan Clothianidin'in oldukça kararlı davrandığı, konsantrasyonunda herhangi bir değişim olmadığı görülmüştür.

- $\mathrm{TiO}_{2}$ varlığında yapılan UV-A uygulaması, herhangi bir giderim etkisi göstermeyen UV-A uygulamasına göre uygulama süresiyle artan bir Clothianidin giderim eğilimiyle sonuçlanmıştır. 120 dakikalık $\mathrm{UV}-\mathrm{A}+\mathrm{TiO}_{2}$ uygulaması sonucunda $\% 42$ oranında Clothianidin giderimi elde edilmiştir.

- $\mathrm{UV}-\mathrm{A}+\mathrm{TiO}_{2}$ uygulamasına oksijen ilave edildiğinde Clothianidin gideriminin 120 dakika sonunda \%42'den \%69 düzeyine ulaşabildiği görülmüştür.

- Sadece UV-C ışınına maruz bırakılan Clothianidin ilk 5 dakikada neredeyse \%100'e varan bir verimle bozunmaya uğramıştır.

Clothianidin giderimi için elde edilen sonuçlar Tablo 1'de verilmektedir.

Tablo 1. Uygulanan fotokatalitik yöntemlerle elde edilen Clothianidingiderim düzeyleri

\begin{tabular}{lcc}
\hline \multicolumn{1}{c}{ Uygulama } & Süre (dk) & Giderim verimi \\
\hline $\mathrm{UV}-\mathrm{A}$ & 120 & Giderim gözenmedi. \\
$\mathrm{UV}-\mathrm{A}+\mathrm{TiO}_{2}$ & 120 & $\% 42$ \\
$\mathrm{UV}-\mathrm{A}+\mathrm{TiO}_{2}+\mathrm{O}_{2}$ & 120 & $\% 69$ \\
$\mathrm{UV}-\mathrm{C}$ & 5 & $\% 99$ \\
\hline
\end{tabular}

UV-C uygulamasının Clothianidin gideriminde hem çok kısa bir sürede sonuç verdiği ve hem de yüksek bir verim sağladığı gözlenmiştir. Suyun içerisinde çözünmüş halde bulunan Clothianidin neonikotinoidini arıtmak üzere kullanılabilecek UV-C uygulamasının avantajı hiçbir kimyasal madde ilavesine gerek kalmadan tek başına \%100'e yakın bir oranda giderim sağlamasıdır. Clothianidin içeren atıksuların arıtımında UV-C uygulamalarının kısa sürede etkili bir çözüm sunacağı düşünülmektedir.

\section{Kaynakça}

Affam, A. C., \& Chaudhuri, M. (2013). Degradation of pesticides chlorpyrifos, cypermethrin and chlorothalonil in aqueous solution by TiO2 photocatalysis. Journal of Environmental Management, 130, 160-165. doi: 10.1016/j.jenvman.2013.08.058

Anderson, J. C., Dubetz, C., \& Palace, V. P. (2015). Neonicotinoids in the Canadian aquatic environment: A literature review on current use products with a focus on fate, exposure, and biological effects. Science of The Total Environment, 505, 409-422. doi: 10.1016/j.scitotenv.2014.09.090

Badawy, M. I., Ghaly, M. Y., \& Gad-Allah, T. (2006). Advanced oxidation processes for the removal of organophosphorus pesticides from wastewater. 194(1-3), 166-175.

Banic, N. D., Abramovic, B. F., Sojic, D. V., Krstic, J. B., Fincur, N. L., \& Bakovic, I. P. (2016). Efficiency of neonicotinoids photocatalytic degradation by using annular slurry reactor. Chemical Engineering Journal, 286, 184-190. doi: 10.1016/j.cej.2015.10.076

Burrows, H. D., Canle, M., Santaballa, J. A., \& Steenken, S. (2002). Reaction pathways and mechanisms of photodegradation of pesticides. Journal of Photochemistry and Photobiology B-Biology, 67(2), 71-108. doi: Doi 10.1016/S1011-1344(02)00277-4

Bustos, N., Cruz-Alcalde, A., Iriel, A., Cirelli, A. F., \& Sans, C. (2019). Sunlight and UVC-254 irradiation induced photodegradation of organophosphorus pesticide dichlorvos in aqueous matrices. Science of The Total Environment, 649, 592-600. doi: 10.1016/j.scitotenv.2018.08.254

Cernigoj, U., Stangar, U. L., \& Trebse, P. (2007). Degradation of neonicotinoid insecticides by different advanced oxidation processes and studying the effect of ozone on TiO2 photocatalysis. Applied Catalysis B-Environmental, 75(3-4), 229-238. doi: 10.1016/j.apcatb.2007.04.014

Chiron, S., Fernández-Alba, A. R., Rodriguez, A., \& García-Calvo, E. (2000). Pesticide chemical oxidation: state-of-the-art. Water Research, 34, 366-377.

Chu, W., \& Wong, C. C. (2004). The photocatalytic degradation of dicamba in TiO(2) suspensions with the help of hydrogen peroxide by different near UV irradiations. Water Research, 38(4), 1037-1043. doi: 10.1016/j.watres.2003.10.037

De Laat, J., Gallard, H., Ancelin, S., \& Legube, B. (1999). Comparative study of the oxidation of atrazine and acetone by H2O2/UV, $\mathrm{Fe}(\mathrm{III}) / \mathrm{UV}, \mathrm{Fe}(\mathrm{III}) / \mathrm{H} 2 \mathrm{O} 2 / \mathrm{UV}$ and $\mathrm{Fe}(\mathrm{II})$ or $\mathrm{Fe}(\mathrm{III}) / \mathrm{H} 2 \mathrm{O} 2$. Chemosphere, 39(15), 2693-2706. doi: Doi 10.1016/S00456535(99)00204-0

EU. (2013). Commission Implementing Regulation (EU) No 485/2013 of 24 May 2013. Official Journal of the European Union, $L$ $139 / 12$.

Fırat, Ö., \& Aytekin, T. (2018). Neonikotinoid insektisit thiamethoxamın Oreochromis niloticus'ta oksidatif stres parametreleri üzerine etkisi. BAUN Fen Bil. Enst. Dergisi, 20(2), 224-234. 
Fujishima, A., \& Zhang, X. T. (2006). Titanium dioxide photocatalysis: present situation and future approaches. Comptes Rendus Chimie, 9(5-6), 750-760. doi: 10.1016/j.crci.2005.02.055

Goulson, D. (2013). REVIEW: An overview of the environmental risks posed by neonicotinoid insecticides. Journal of Applied Ecology, 50(4), 977-987. doi: 10.1111/1365-2664.12111

Hashimoto, K., Irie, H., \& Fujishima, A. (2005). TiO2 photocatalysis: A historical overview and future prospects. Japanese Journal of Applied Physics Part 1-Regular Papers Brief Communications \& Review Papers, 44(12), 8269-8285. doi: 10.1143/Jjap.44.8269

Jeschke, P., \& Nauen, R. (2008). Neonicotinoids - from zero to hero in insecticide chemistry. Pest Management Science, 64(11), 10841098. doi: 10.1002/ps.1631

Jeschke, P., Nauen, R., Schindler, M., \& Elbert, A. (2011). Overview of the Status and Global Strategy for Neonicotinoids. Journal of Agricultural and Food Chemistry, 59(7), 2897-2908. doi: 10.1021/jf101303g

Kohler, H. R., \& Triebskorn, R. (2013). Wildlife Ecotoxicology of Pesticides: Can We Track Effects to the Population Level and Beyond? science, 341(6147), 759-765. doi: 10.1126/science.1237591

Konstantinou, I. K., \& Albanis, T. A. (2003). Photocatalytic Transformation of Pesticides in Aqueous Titanium Dioxide Suspensions Using Artificial and Solar Light: Intermediates and Degradation Pathways. Applied Catalysis B: Environmental, 42, $319-335$.

Kovganko, N. V., \& Kashkan, Z. N. (2004). Advances in the synthesis of neonicotinoids. Russian Journal of Organic Chemistry, 40(12), 1709-1726. doi: DOI 10.1007/s11178-005-0089-y

Le, T. D. H., Scharmuller, A., Kattwinkel, M., Kuhne, R., Schuurnann, G., \& Schafer, R. B. (2017). Contribution of waste water treatment plants to pesticide toxicity in agriculture catchments. Ecotoxicology and Environmental Safety, 145, 135-141. doi: 10.1016/j.ecoenv.2017.07.027

Lorret, O., Francova, D., Waldner, G., \& Stelzer, N. (2009). W-doped titania nanoparticles for UV and visible-light photocatalytic reactions. Applied Catalysis B-Environmental, 91(1-2), 39-46. doi: 10.1016/j.apcatb.2009.05.005

Martin, M. M. B., Perez, J. A. S., Lopez, J. L. C., Oller, I., \& Rodriguez, S. M. (2009). Degradation of a four-pesticide mixture by combined photo-Fenton and biological oxidation. Water Research, 43(3), 653-660. doi: 10.1016/j.watres.2008.11.020

Pašková, V., Hilscherová, K., Bláha, L. (2011). Teratogenicity and Embryotoxicity in Aquatic Organisms After Pesticide Exposure and the Role of Oxidative Stress. Reviews of Environmental Contamination and Toxicology. 211, 25-61, doi: 10.1007/978-1-44198011-3_2.

Schneider, J., Matsuoka, M., Takeuchi, M., Zhang, J. L., Horiuchi, Y., Anpo, M., \& Bahnemann, D. W. (2014). Understanding TiO2 Photocatalysis: Mechanisms and Materials. Chemical Reviews, 114(19), 9919-9986. doi: 10.1021/cr5001892

TOB. (2018). Neonicotinoid Grubu Aktif Maddelerin Yasaklanması ve Kısitlanması Kararı. TC Tarım ve Orman Bakanlı̆̆l, Glda ve Kontrol Genel Müdürlügü, Karar Yazısl, Sayl :81466379-320.04.02-E.3768012, Tarih: 19.12.2018.

Tokumoto, J., Danjo, M., Kobayashi, Y., Kinoshita, K., Omotehara, T., Tatsumi, A., . . Hoshi, N. (2013). Effects of Exposure to Clothianidin on the Reproductive System of Male Quails. Journal of Veterinary Medical Science, 75(6), 755-760. doi: 10.1292/jvms. 12-0544

USEPA. (2003). Fact Sheet for Clothianidin. United States Environmental Protection Agency (7501C), Office of Prevention, Pesticides and Toxic Substances, Name of Chemical: Clothianidin, Reason for Issuance: Conditional Registration, Date Issued: May 30, 2003.

Whitehorn, P. R., O'Connor, S., Wackers, F. L., \& Goulson, D. (2012). Neonicotinoid Pesticide Reduces Bumble Bee Colony Growth and Queen Production. science, 336(6079), 351-352. doi: 10.1126/science.1215025

Yamamoto, A., Terao, T., Hisatomi, H., Kawasaki, H., \& Arakawa, R. (2012). Evaluation of river pollution of neonicotinoids in Osaka City (Japan) by LC/MS with dopant-assisted photoionisation. Journal of Environmental Monitoring, 14(8), 2189-2194. doi: $10.1039 / \mathrm{c} 2 \mathrm{em} 30296 \mathrm{a}$

Zabar, R., Dolenc, D., Jerman, T., Franko, M., \& Trebse, P. (2011). Photolytic and photocatalytic degradation of 6-chloronicotinic acid. Chemosphere, 85(5), 861-868. doi: 10.1016/j.chemosphere.2011.06.107 